\title{
Article \\ Eight-Year Retrospective Study of Young Adults in a Diabetes Transition Clinic
}

\author{
Aarooran Sritharan ${ }^{1}$, Uchechukwu L. Osuagwu ${ }^{1,2}$, Manjula Ratnaweera ${ }^{3}$ and David Simmons ${ }^{1,2,4, *(\mathbb{D})}$ \\ 1 Diabetes, Obesity and Metabolism Translational Research Unit, School of Medicine, \\ Western Sydney University, Campbelltown, NSW 2560, Australia; aaroorans@gmail.com (A.S.); \\ l.osuagwu@westernsydney.edu.au (U.L.O.) \\ 2 Translational Health Research Unit (THRI), School of Medicine, Western Sydney University, \\ Campbelltown, NSW 2560, Australia \\ 3 Waikato Hospital, Hamilton 3240, New Zealand; Manjula.Ratnaweera@waikatodhb.health.nz \\ 4 Macarthur Diabetes Endocrinology and Metabolism Service, Campbelltown Hospital, \\ Campbelltown, NSW 2560, Australia \\ * Correspondence: da.simmons@westernsydney.edu.au; Tel.: +61-2-4620-3899
}

Citation: Sritharan, A.; Osuagwu, U.L.; Ratnaweera, M.; Simmons, D. Eight-Year Retrospective Study of Young Adults in a Diabetes Transition Clinic. Int. J. Environ. Res. Public Health 2021, 18, 12667. https:// doi.org/10.3390/ijerph182312667

Academic Editors: Ryan D. Burns and Wonwoo Byun

Received: 10 November 2021 Accepted: 28 November 2021 Published: 1 December 2021

Publisher's Note: MDPI stays neutral with regard to jurisdictional claims in published maps and institutional affiliations.

Copyright: () 2021 by the authors. Licensee MDPI, Basel, Switzerland. This article is an open access article distributed under the terms and conditions of the Creative Commons Attribution (CC BY) license (https:// creativecommons.org/licenses/by/ $4.0 /)$.

\begin{abstract}
The transition of people from paediatric to adult diabetes services is associated with worsening glycaemia and increased diabetes-related hospitalisation. This study compared the clinical characteristics of those with and without mental health conditions among attenders at a diabetes young adult clinic diabetes before and after changes in service delivery. Retrospective audit of 200 people with diabetes attending a Sydney public hospital over eight years corresponding to the period before (2012-2016) and after (2017-2018) restructuring of a clinic for young adults aged 16-25 years. Characteristics of those with and without mental health conditions (depression, anxiety, diabetes related distress, eating disorders), were compared. Among clinic attenders (type 1 diabetes $n=184,83.2 \%), 40.5 \%(n=89)$ had a mental health condition particularly, depression $(n=57,64 \%)$, which was higher among Indigenous than non-Indigenous people $(5.6 \%$ vs. $0.8 \%, p=0.031)$ but similar between diabetes type. Over eight years, those with, compared with those without a mental health condition had higher haemoglobin A1c $(\mathrm{HbA} 1 \mathrm{c})$ at the last visit $(9.4 \%(79 \mathrm{mmol} / \mathrm{mol})$ vs $8.7 \%(71 \mathrm{mmol} / \mathrm{mol}), p=0.027)$, the proportion with diabetic ketoacidosis (DKA $60.7 \%$ vs. $42.7 \%$, $p=0.009$ ), smoking (38.4 vs. $13.6 \%, p=0.009$ ), retinopathy ( 9.0 vs. $2.3 \%, p=0.025$ ), multiple DKAs ( 28.4 vs. $16.0 \%, p=0.031$ ) were significantly higher. Having a mental health condition was associated with 2.02 (95\% confidence intervals 1.1-3.7) fold increased risk of $\mathrm{HbA} 1 \mathrm{c} \geq 9.0 \%$ (75 mmol/mol). Changes to the clinic were not associated with improvements in mental health condition (39.0\% vs. $32.4 \%, p=0.096$ ). In conclusion, we found that mental health conditions, particularly depression, are common in this population and are associated with diabetes complications. Diabetes type and clinic changes did not affect the reported mental health conditions. Additional strategies including having an in-house psychologist are required to reduce complication risks among those with mental health conditions.
\end{abstract}

Keywords: diabetic ketoacidosis; mental health; type 1 diabetes; transition; glycaemia

\section{Introduction}

The transition of people from paediatric to adult diabetes services is associated with worsening glycaemia and increased diabetes-related hospitalisation [1]. This transition period correlates with increased risk-seeking behaviour including drugs, alcohol and unsafe sex [1] The transition period generally corresponds to people moving out of home alongside changes in social and employment situations, and is associated with emotional and financial hardship. Under such circumstances, several people lose continuity of professional care, which may affect outcomes [2]. Poor glycaemic control and mental health conditions, such as depression, anxiety, eating disorders and diabetes distress, are common in this population $[3,4]$. However, diagnoses of mental health conditions are often missed, misdiagnosed or poorly managed exacerbating the poorer prognosis of affected young people [5,6]. 
The increased prevalence of diabetes in adolescence and young adulthood around the world warrants effective treatment models and guidelines for healthcare professionals involved in their care [2]. Implementing a well-structured program for these transitioning young adults is pivotal for long-term outcomes and continued compliance with diabetes self-management [4,7]. Such programs should include education for paediatric care providers, pre-pregnancy programs for women [8], and screening for mental health co-morbidities [3], thus optimising transition of care from paediatric to adult clinic. The transition conversations should happen early with the care appropriately tailored to the developmental level and unique needs of emerging adults [9]. These strategies may improve glycaemia, reduce the frequency of diabetic ketoacidosis (DKA)-related hospitalisations, and improve clinic attendance $[4,10]$, thereby reducing short term personal and financial burden [11]. Maintaining lower haemoglobin $\mathrm{A} 1 \mathrm{c}(\mathrm{HbA} 1 \mathrm{c})$ in people over a long period of time reduces complications and improves quality of life with added economic benefits [12]. This study compared glycaemia and hospitalisation risks of people attending a diabetes transition clinic with and without mental health conditions, as well as the effects of clinic structural changes on the outcomes.

\section{Subjects and Methods}

A tertiary public hospital located in Sydney, one of the few major city hospitals with a transition diabetes service situated in the same facility as the paediatric diabetes service. The hospital serves 3 local government areas with an estimated population of 283,743 residents in 2016, including 38,622 (13.6\%) aged 15-24 years [13] of whom approximately 400 were known to be living with diabetes [14].

\subsection{The Diabetes Transition Clinic}

The diabetes transition clinic is a multidisciplinary (endocrinologist, educator, dietitian) clinic that commenced in 2011 with one of the educators serving as a coordinator [15]. Diabetes educators are clinicians who specialise in the provision of diabetes self-management education for people with diabetes. People were considered to have a mental health condition if there had been a formal diagnosis by either a psychiatrist, psychologist or general practitioner and/or following an assessment by the diabetes educator or endocrinologist. Mental health support was provided through the youth health service or through communication with the general practitioner for referral to a private psychologist in the community.

An audit of our clinic conducted in 2016 [6] showed high rates of mental health comorbidities (59\%), DKA-related hospitalisations since diagnosis (39\%) and prior pregnancies $(23 \%)$. These prompted a re-assessment of the clinic's mode of operation in the latter half of 2016, including the introduction of an afternoon clinic operating from 3.00-8.00 p.m. (previously a Monday morning clinic) to optimise clinic attendances of those with strict working or studying schedules, a second diabetes educator, the use of structured clinic sheets for documentation of consultations and greater links with youth health services. Continuous glucose monitoring systems (CGMS) became more accessible for selected young adults (up to 21 years) through a Federal Government programme. A separate lounge with a television system was provided for entertainment and display of information.

The target levels for optimal control of the clinical measures were set as: $\mathrm{HbA} 1 \mathrm{c} \leq 7.0 \%$ for type 1 diabetes and $\leq 6.5 \%$ for type 2 diabetes, systolic blood pressure (sBP) $<130 \mathrm{~mm} \mathrm{Hg}$, diastolic blood pressure $(\mathrm{dBP})<80 \mathrm{~mm} \mathrm{Hg}$, total cholesterol $\leq 5.0 \mathrm{mmol} / \mathrm{L}$, total triglycerides (TAGs) $<2.0 \mathrm{mmol} / \mathrm{L}$, high density lipoprotein (HDL) cholesterol $>1.0 \mathrm{mmol} / \mathrm{L}$, and low-density lipoprotein of LDL $<2.5 \mathrm{mmol} / \mathrm{L}$ [16].

\subsection{Data Collection}

The South Western Sydney Local Health Research Ethics Committee (LNR/16/LPOOL/180) approved the study. People were included if they were referred to the transition clinic (aged 16-25 years) between 2012 and 2019. Patient demographics, sources of referrals, 
metabolic, attendance, reasons for leaving the clinic and clinical history data were collected. Nephropathy included microalbuminuria (albumin/creatinine ratio (ACR) $\geq 2.5 \mathrm{mg} / \mathrm{mmol}$ for males and $\geq 3.5 \mathrm{mg} / \mathrm{mmol}$ for females), retinopathy was confirmed by an optometrist or ophthalmologist, and neuropathy by a clinical assessment. Glycaemia was measured either using a point-of-care $\mathrm{HbA1c}$ machine (Bayer DCA 2000 Blood Analyser, NSW, Australia), at the hospital laboratory (HPLC on Bio-Rad Variant II methodology), or through external pathology providers. Change in $\mathrm{HbA1c}$ over time was calculated as last $\mathrm{HbA1c}$ within the year minus first $\mathrm{HbA} 1 \mathrm{c}$. Driving requirement compliance refers to the recommendation, which requires the people to check their blood glucose level regularly before driving, carry quick acting carbohydrates and ensure that the reading is $\geq 5 \mathrm{mmol} / \mathrm{L}$ to avoid hypoglycaemia while driving.

\subsection{Statistical Analysis}

SPSS Version 26 (IBM Australia, St Leonards, NSW, Australia) was used for data analysis. One-way ANOVA was used to compare continuous variables and Chi-square test for proportions. An independent samples median test of the HbA1c at the end of the second year in clinic was conducted to compare the change in $\mathrm{HbA1}$ c from the baseline (commencement of clinic), before and after changes to the clinic were implemented. Binomial logistic regression was conducted to assess the impact of mental health on glycaemia, having one or more DKA events, and other diabetes complications. Age and diabetes duration were taken as continuous variables. The binomial regression was repeated, without $\mathrm{HbA} 1 \mathrm{c}$ (model 2) to assess the impact of mental health conditions on DKA risk with the existing degree of hyperglycaemia. Indigenous status was excluded in the logistic regression due to small numbers. All tests were two tailed and $p<0.05$ were considered significant. The calculated standardized mortality ratio (SMR: Observed/expected number of deaths (using Australian Bureau of Statistics [ABS] data) $\times 100$ ) under or over 100 indicates lower or higher mortality compared with the general population in the same age group $(0.4 / 1000$ in the 20-25-year age group).

\section{Results}

\subsection{Characteristics}

Figure 1 shows that of the 260 referred people, $66 \%$ attended via the local paediatric diabetes clinic. The mean age at first assessment was $19.2 \pm 1.8$ years (range, 16-24 years), median attendance at the transition clinic was 1.0 (range, 7.9) years and had between 1-15 attendances (average of 4 times), over the study period as shown in Table 1.

Overall, $11.5 \%$ never attended the clinic, $7 \%$ were lost to follow up after one clinic visit, and $20 \%$ transferred to another service, including thirty-three patients aged below 25 years $(15 \%)$ at the time of transfer (Figure 1). The referral rate increased in 2018-2019. Three of the 260 people who were referred to the clinic died between 2012-2019 (11.5 deaths (95\%CI..6 to 24.7) per 1000 people over 8 years) equivalent to an annual death rate of 1.4 per 1000 and a standardizsed mortality ratio of 350 . Overall, $83.6 \%$ had type 1 diabetes, $14.1 \%$ type 2 diabetes and the rest (2.3\%) had monogenic diabetes (MODY1, MODY3 or MODY4, $n=5)$.

Table 2 presents the clinical profile of the young adults, their treatment modalities and the diabetes-related complications reported in the transition clinic during the study period. Participants were mostly overweight, about one-third of them had hypertension and $21.1 \%$ had experienced multiple episodes of DKA over the study period. Insulin only treatment was predominant in this population and there was a reasonable proportion $(n=18,50.0 \%)$ that were on Oral/GLP1 treatment only. 


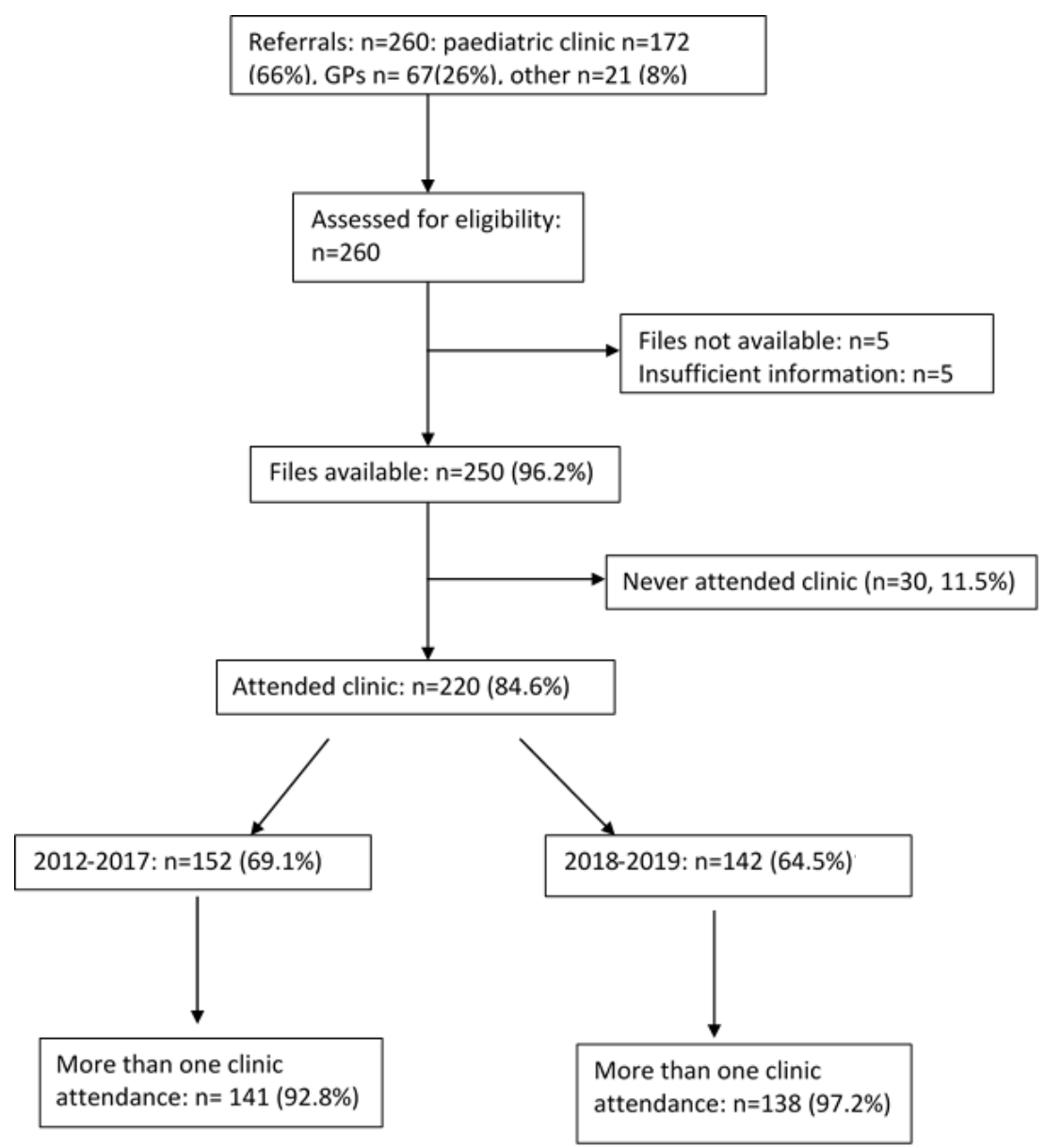

Figure 1. Flow of people in this study. The $=\%$ add up to more than $100 \%$ because 74 attended during both audits, 78 only in audit 1 and 68 only in audit 2.

Table 1. Characteristics of the sample population with diabetes in the transition clinic (2012-2018).

\begin{tabular}{|c|c|}
\hline Variables & All \\
\hline $\mathrm{N}(\%)$ & 220 \\
\hline \multicolumn{2}{|l|}{ Period } \\
\hline 2012-2016 & $78(35.5)$ \\
\hline 2019-2019 & $68(30.9)$ \\
\hline 2012-2019 & 74 (33.6) \\
\hline \multicolumn{2}{|l|}{ Socio-demography } \\
\hline Current age, mean (SD) & $22.6(3.1)$ \\
\hline Age at first assessment, mean (SD) & $18.6(2.0)$ \\
\hline Female, $n(\%)$ & $92(44.5)$ \\
\hline Place of Birth-Australia & 205 (93.2) \\
\hline Aboriginal or Torres Strait Island & $6(2.7)$ \\
\hline Smoking, $n(\%)$ & $44(20.0)$ \\
\hline Alcohol, $n(\%)$ & $108(49.1)$ \\
\hline \multicolumn{2}{|l|}{ Diabetes type } \\
\hline Type 1 diabetes & $184(83.6)$ \\
\hline Type 2 diabetes/Other & $36(16.4)$ \\
\hline \multicolumn{2}{|l|}{ Glycaemia, mean (SD) } \\
\hline $\mathrm{HbAlc}$ at entry, $\%(\mathrm{mmol} / \mathrm{mol})$ & $9.9 \pm 2.6(84 \pm 29)$ \\
\hline Mean $\mathrm{HbA1c}$ & $9.2 \pm 2.0(77 \pm 22)$ \\
\hline $\mathrm{HbA} 1 \mathrm{c}$ at last visit, $\%(\mathrm{mmol} / \mathrm{mol})$ & $8.9 \pm 2.3(74 \pm 25)$ \\
\hline Reduction in $\mathrm{HbA} 1 \mathrm{c}$ since first attendance, $\%(\mathrm{mmol} / \mathrm{mol})$ & $0.9 \pm 2.8(10.1 \pm 29.8)$ \\
\hline Driving requirement compliance, $n(\%)$ & $89(40.5)$ \\
\hline Age of diagnosis (years), mean (SD) & $12.2 \pm 5.9$ \\
\hline Diabetes duration (years), mean (SD) & $9.8 \pm 6.3$ \\
\hline Number of clinic check ins, mean (SD) & $6.1 \pm 5.0$ \\
\hline Number of years in clinic, mean (SD) & $2.2 \pm 1.7$ \\
\hline
\end{tabular}


Table 2. Metabolic outcomes, treatment and complications of the sample population with diabetes in the transition clinic (2012-2018).

\begin{tabular}{|c|c|}
\hline Variables & All \\
\hline \multicolumn{2}{|c|}{ Metabolic outcomes, mean (standard deviation) } \\
\hline \multicolumn{2}{|l|}{ Lipids $(\mathrm{mmol} / \mathrm{L})$} \\
\hline Mean total cholesterol & $4.7 \pm 1.1$ \\
\hline Mean TAGs & $1.8 \pm 1.8$ \\
\hline Mean HDL & $1.4 \pm 0.4$ \\
\hline Mean LDL & $2.7 \pm 0.8$ \\
\hline \multicolumn{2}{|l|}{ Blood pressures (mmHg) } \\
\hline Mean of mean sBP & $124 \pm 11$ \\
\hline Mean of mean dBP & $75 \pm 7$ \\
\hline $\operatorname{BMI}\left(\mathrm{kg} / \mathrm{m}^{2}\right)$ & $28.0 \pm 7.7$ \\
\hline \multicolumn{2}{|l|}{ Treatment, $n(\%)$} \\
\hline Insulin only & $169(76.8)$ \\
\hline Insulin and oral/GLP1 & $35(15.9)$ \\
\hline Oral/GLP1 only ${ }^{a}$ & $18(50.0)$ \\
\hline \multicolumn{2}{|l|}{ Complications, $n(\%)$} \\
\hline Neuropathy & $17(7.7)$ \\
\hline Nephropathy ${ }^{+}$ & $34(15.5)$ \\
\hline Retinopathy & $11(5.0)$ \\
\hline Any long-term complication, $n(\%)$ & $34(15.5)$ \\
\hline Hypertension, $n(\%)$ & $77(35.0)$ \\
\hline Mental health condition, $n(\%)$ & $89(40.5)$ \\
\hline $\mathrm{DKA}^{\dagger}, n(\%)$ & $110(50.0)$ \\
\hline Multiple DKA episodes, $n(\%)$ & $46(21.1)$ \\
\hline Hypoglycaemia admissions, $n(\%)$ & $24(10.9)$ \\
\hline Multiple hypo episodes, $n(\%)$ & $6(2.8)$ \\
\hline Any long-term complication, $n(\%)$ & $34(15.5)$ \\
\hline Hypertension, $n(\%)$ & $77(35.0)$ \\
\hline \multicolumn{2}{|l|}{ Target achieved, $n(\%)$} \\
\hline $\mathrm{sBP}<130 \mathrm{~mm} \mathrm{Hg}$ & $142(71.4)$ \\
\hline $\mathrm{dBP}<80 \mathrm{mmHg}$ & $148(74.4)$ \\
\hline $\mathrm{HbA} 1 \mathrm{c} * *$ & $23(10.7)$ \\
\hline Total cholesterol $<5.0 \mathrm{mmol} / \mathrm{L}$ & $106(66.7)$ \\
\hline Total TAGs $<2.0 \mathrm{mmol} / \mathrm{L}$ & $122(76.7)$ \\
\hline Total HDL > $1.0 \mathrm{mmol} / \mathrm{L}$ & $116(81.7)$ \\
\hline Total LDL $<2.5 \mathrm{mmol} / \mathrm{L}$ & $61(43.9)$ \\
\hline \multicolumn{2}{|c|}{$\begin{array}{l}\text { Metformin only in those with type } 2 \text { diabetes. Abbreviations: } \mathrm{HbA1c}=\text { haemoglobin } \mathrm{A} 1 \mathrm{c} ; \mathrm{GLP} 1=\text { Glucagon-like } \\
\text { peptide- } 1 \text { Receptor agonist; } \mathrm{DKA}=\text { diabetic ketoacidosis; } \mathrm{TAG}=\text { triglycerides; } \mathrm{HDL}=\text { high density lipoprotein; } \\
\mathrm{LDL}=\text { low density lipoprotein; } \mathrm{sBP}=\text { systolic blood pressure; } \mathrm{dBP}=\text { diastolic blood pressure; } \mathrm{BMI}=\text { body mass } \\
\text { index }{ }^{+}>2.5 \mathrm{mg} / \mathrm{mmol} \text { for males and }>3.5 \mathrm{mg} / \mathrm{mmol} \text { for females. } * * \leq 7 \%(53 \mathrm{mmol} / \mathrm{mol}) \text { for people with } \\
\text { Type } 1 \text { diabetes and } \leq 6.5 \% \text { ( } 48 \mathrm{mmol} / \mathrm{mol} \text { ) for those with type } 1 \text { diabetes } / \text { Other types of diabetes. } p \text { values were } \\
\text { Chi-square test for discrete variables and t-test for continuous variables. }\end{array}$} \\
\hline
\end{tabular}

\subsection{Comparison of People with and without Mental Health Conditions}

In this transition clinic, mental health conditions were common $(n=89,40.5 \%$ with more than one often being present) including depression (57, $64 \%$ of those with a mental health condition) anxiety $(29,33 \%)$, diabetes related distress $(20,22 \%)$, and eating disorders $(4,4.5 \%)$. There were six Aboriginal people in this study, five of whom $(83.3 \%)$ had a mental health condition.

Table 3 compares the characteristics of people with and without a mental health condition. Despite having similar duration of diabetes, people with a mental health condition had a significantly higher $\mathrm{HbA} 1 \mathrm{c}$ at their last clinic appointment, higher episodes of DKA-related hospitalisations, recurrent hospitalisations associated with DKAs and more long-term complications compared with those without a mental health condition. Smoking was over twice as common in people with a mental health condition. Between 2012-2017, three documented referrals to the youth health service occurred, with a further five referrals in 2018-2019. Only one encounter with a private psychologist was documented. The use 
of CGM was comparable between those with and without mental health condition (57.6\% vs. $65.1 \%, p=0.359)$ with similar rate of pregnancies $(27.3 \%$ vs. $16.7 \%, p=0.207)$. The proportion of patients who achieved target metabolic measures were largely comparable across metabolic measures.

Table 3. Comparison of people with and without mental health conditions.

\begin{tabular}{|c|c|c|c|}
\hline Variables & $\begin{array}{c}\text { Mental Health } \\
\text { Conditions }(n=89)\end{array}$ & $\begin{array}{l}\text { No Mental Health } \\
\text { Conditions }(n=131)\end{array}$ & $p$ Value \\
\hline Current age, mean $( \pm S D)$ years & $22.8(2.8)$ & $22.5(3.2)$ & 0.816 \\
\hline Age at first assessment, mean $( \pm S D)$ years & $18.7(1.96)$ & $18.6(2.0)$ & 0.816 \\
\hline Gender & $45(50.6)$ & 77 (59.2) & \multirow{3}{*}{0.205} \\
\hline Male, $n(\%)$ & $\begin{array}{l}45(50.6) \\
44(49.4)\end{array}$ & $53(40.8)$ & \\
\hline Female, $n(\%)$ & $44(49.4)$ & $53(40.8)$ & \\
\hline Type of Diabetes & 74 (83.1) & 109 (83.8) & \multirow{3}{*}{0.891} \\
\hline $1, n(\%)$ & $15(169)$ & $21(16.2)$ & \\
\hline 2/other, $n(\%)$ & $15(16.9)$ & $21(16.2)$ & \\
\hline Aboriginal or Torres Strait Islander status, $n(\%)$ & $5(5.6)$ & $1(0.8)$ & 0.031 \\
\hline DKA, $n(\%)$ & $54(60.7)$ & $56(42.7)$ & 0.009 \\
\hline Multiple DKA, $n(\%)$ & $25(28.4)$ & $21(16.0)$ & 0.031 \\
\hline Hypoglycaemia admissions, $n(\%)$ & $12(13.5)$ & $12(9.2)$ & 0.313 \\
\hline Multiple hypoglycaemia events, $n(\%)$ & $4(4.5)$ & $2(1.5)$ & 0.185 \\
\hline Neuropathy, $n(\%)$ & $8(9.0)$ & $9(6.9)$ & 0.564 \\
\hline Nephropathy ${ }^{\dagger}, n(\%)$ & $6(6.7)$ & $4(3.1)$ & 0.197 \\
\hline Retinopathy, $n(\%)$ & $8(9.0)$ & $3(2.3)$ & 0.025 \\
\hline Any long-term complication, $n(\%)$ & $20(22.5)$ & $15(11.5)$ & 0.028 \\
\hline Hypertension, $n(\%)$ & $32(36)$ & $45(34.6)$ & 0.838 \\
\hline Smoking, $n(\%)$ & $27(30.3)$ & $17(13.1)$ & 0.005 \\
\hline Alcohol, $n(\%)$ & $41(46.1)$ & $67(51.5)$ & 0.460 \\
\hline Driving requirement compliance, $n(\%)$ & $33(37.1)$ & $56(42.1)$ & 0.071 \\
\hline $\mathrm{HbA} 1 \mathrm{c}$ at entry, $\%(\mathrm{mmol} / \mathrm{mol})$ & $\begin{array}{l}10.2 \pm 2.6 \\
(89 \pm 29)\end{array}$ & $\begin{array}{l}9.6 \pm 2.6 \\
(82 \pm 29)\end{array}$ & 0.083 \\
\hline Last $\mathrm{HbA} 1 \mathrm{c}, \%(\mathrm{mmol} / \mathrm{mol})$ & $\begin{array}{l}9.4 \pm 2.4 \\
(79 \pm 27)\end{array}$ & $\begin{array}{l}8.7 \pm 2.2 \\
(71 \pm 24)\end{array}$ & 0.027 \\
\hline Target HDL, $n(\%)$ & $41(46.1)$ & $75(57.3)$ & 0.046 \\
\hline Age at diagnosis, years & $11.3 \pm 5.8$ & $12.1 \pm 5.9$ & 0.060 \\
\hline Diabetes duration, years & $10.7 \pm 6.4$ & $9.1 \pm 6.2$ & 0.056 \\
\hline Number of clinic check ins & $5.6 \pm 4.0$ & $6.6 \pm 5.3$ & 0.229 \\
\hline Number of years in clinic & $1.8 \pm 1.5$ & $2.1 \pm 2.0$ & 0.389 \\
\hline
\end{tabular}

Abbreviations: $\mathrm{HbA1c}=$ Haemoglobin A1c; DKA $=$ diabetic ketoacidosis ${ }^{\dagger}>2.5 \mathrm{mg} / \mathrm{mmol}$ for males and $>3.5 \mathrm{mg} / \mathrm{mmol}$ for females $p$ values were Chi-square test for discrete variables and $t$-test for continuous variable.

Table 4 presents the adjusted odds ratio and $95 \%$ confidence intervals of factors associated with mental health condition in this study population. Having an $\mathrm{HbA1c}>9 \%(75 \mathrm{mmol} / \mathrm{mol})$ was the only factor associated with mental health conditions after adjusting for other potential confounders (adjusted odds ratio 2.02, 95\% confidence intervals CI 1.10, 3.70). The relationship between mental health conditions and any DKA episode became significant after $\mathrm{HbA1}$ was removed from the model (adjusted odds ratio $2.15,95 \%$ CI 1.13, 4.07). 
Table 4. Unadjusted (OR) and adjusted odd ratios (aOR: 95\%confidence intervals) of factors associated with mental health condition among young adults attending the diabetes transition clinic. Bolded CIs are significant associations.

\begin{tabular}{|c|c|c|c|c|c|c|}
\hline & Model 1 & & & Model 2 & & \\
\hline Variables & OR & $\mathrm{aOR}[95 \% \mathrm{CI}]$ & $p$-value & OR & $\mathrm{aOR}[95 \% \mathrm{CI}]$ & $p$-value \\
\hline Gender (1) & 0.185 & $1.20[0.67,2.15]$ & 0.533 & 0.162 & $1.18[0.66,2.08]$ & 0.58 \\
\hline Type of Diabetes (1) & 0.386 & $1.47[0.56,3.87]$ & 0.434 & 0.389 & $1.48[0.57,3.82]$ & 0.423 \\
\hline Age (/year) & -0.011 & $0.99[0.89,1.10]$ & 0.832 & -0.013 & $0.99[0.89,1.10]$ & 0.808 \\
\hline Diabetes Duration (/year) & 0.037 & $1.04[0.98,1.10]$ & 0.194 & 0.032 & $1.03[0.98,1.09]$ & 0.249 \\
\hline $\operatorname{HbA1c}(1)$ & 0.704 & $2.02[1.10,3.70]$ & 0.023 & - & - & - \\
\hline DKA (1) & 0.592 & $1.81[0.93,3.50]$ & 0.079 & 0.764 & $2.15[1.13,4.07]$ & 0.019 \\
\hline Hypoglycaemia (1) & 0.212 & $1.24[0.48,3.19]$ & 0.662 & 0.131 & $1.14[0.45,2.92]$ & 0.784 \\
\hline Any microvascular complication (1) & 0.487 & $1.63[0.72,3.66]$ & 0.239 & 0.702 & $2.02[0.92,4.43]$ & 0.08 \\
\hline
\end{tabular}

DKA = Diabetic ketoacidosis; microvascular complications included retinopathy, nephropathy, neuropathy. The dependent variable was presence (1) or absence (0) of mental health condition and the independent variables included: Type of diabetes (type 1 and type 2 diabetes), HbA1c $(\leq 9 \%(\leq 75 \mathrm{mmol} / \mathrm{mol})$ and $>9.0 \%(>75 \mathrm{mmol} / \mathrm{mol}))$, presence $/$ absence of at least one episode of DKA and hypoglycaemia, any long-term complication (Yes/No), and gender (male and female).

\subsection{Glycaemic (HbA1c) Trend in the Clinic before and after Changes in Service Delivery}

The mean $\mathrm{HbA1c}(9.2 \pm 2.3 \% / 77 \pm 25$ versus $8.8 \pm 2.2 \% / 73 \pm 24 \mathrm{mmol} / \mathrm{mol} ; p=0.164)$ and rate of DKA $(23.0 \%, n=35$ versus $14.8 \%, n=21 ; p=0.072)$ were similar before and after changes to the clinic. Figure 2 shows the trend in $\mathrm{HbA1c}$ across the years people attended the clinic compared to the baseline values Compared to baseline glycaemia, there were significant reductions in $\mathrm{HbA1c}$ each consecutive year the people attended the clinic with a mean reduction of $0.7 \%(8 \mathrm{mmol} / \mathrm{mol})(p<0.001)$ and $2.1 \%(23 \mathrm{mmol} / \mathrm{mol}, p=0.016)$ from the baseline entry $\mathrm{HbA} 1 \mathrm{c}$ by the end of years one and seven, respectively. The proportion using CGM also increased before and after changes to the clinic ( $9.7 \%$ versus $59.9 \%, p<0.001)$.

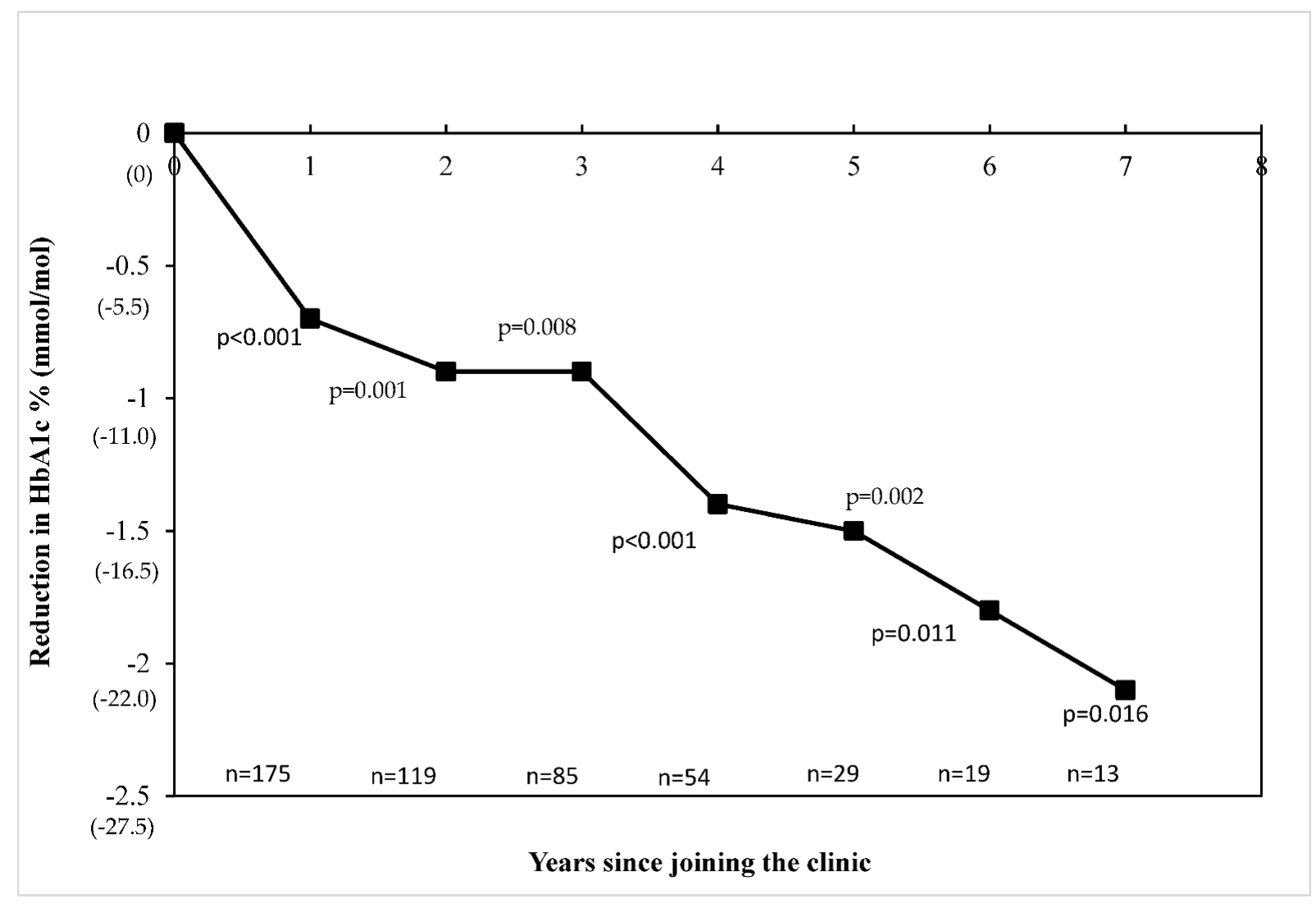

Figure 2. Change in heamoglobin A1c over the years attended clinic. 


\section{Discussion}

We have shown that mental health conditions were common in this population. Those with mental health conditions were more likely to have worse outcomes including poorer glycaemic control, more episodes of DKA, more long-term complications and being more likely to smoker. The proportion with a mental health condition was unaffected by the diabetes type. The mortality rate in this clinic population was high with a standardized mortality rate of 350. Although glycaemia improved substantially with the number of years young adults attended the clinic, there were no significant changes in $\mathrm{HbA1c}$, and a non-significant reduction in DKA, following the changes to the clinic.

Mental health conditions were common in this cohort with higher rates than that reported in the ABS National Survey of Mental Health and Wellbeing [17], with respect to any mental health disorder (26.4 versus $40.5 \%$ in this study), depressive disorder (5.4 versus $33 \%$ ) and anxiety disorder (15.4 versus 64\%) among similar age group (16-24-year-old). Psychosocial conditions although prevalent in transition clinics are often less frequently reported as demonstrated in a recent review of 18 studies, where only $17 \%$ reported on the psychosocial conditions in transition clinics [15]. Since well-structured diabetes transition programmes improve diabetes management and psychological interventions improve glycaemic control in children and adolescents with diabetes [15], the findings of this present study provides further evidence of the need to integrate mental health support as part of the transition clinic. The reason for the high mortality rate is unclear but is likely associated with the high DKA, severe hypoglycaemia rates and the high prevalence of mental health conditions. No documented case of suicide was identified.

Young adults with mental health conditions have worse diabetes outcomes driven by factors including lack of clinic attendance and non-compliance with medications and diet [3]. However, in this study, the number of clinic check ins (attendance) was similar between those with and without mental health condition but the findings of more hyperglycaemia and frequent diabetes related hospitalisations in people with mental health conditions are consistent with the wider literature [6,11]. Prior studies reported difficulties of achieving optimal management of diabetes among young people with mental health conditions [3] and those with diabetes are a high risk group [18]. The stigma of being labelled with a mental health condition and disclosing personal information to another stranger can be frightening to young adults and this complicates the management of diabetes [19]. The low documented rate of youth service/private psychologist review of participants in this study is an indication of communication gap between the clinic and external mental health services which may hinder people from receiving mental health intervention. Thus, having an onsite psychologist may enhance communication, early recognition and management to facilitate optimal diabetes management [3].

The patient's ability to meet target metabolic measures was also affected by their mental health status but significant only for HDL target (Table 2). A past study showed a strong link between dyslipidaemia dysregulations and mental illness with the authors suggesting that the unhealthy lifestyle and a poor adherence to medical regimen, which are prevalent among psychiatric patients, may contribute to this finding in addition to the reported profound influence of specific psychotropic medications on lipid regulations. [20] In this study, the smoking rate was significantly higher among people with diabetes who had a mental health condition compared to those without and as shown in one study, the smoking rate may also increase alongside the severity of the mental health condition [21]. Our findings are in line with past studies that found higher smoking rates in people with mental health conditions compared with the general Australian population [22-24]. The studies also showed that people with mental health condition have higher levels of nicotine dependence [25], and a disproportionate health and financial burden from smoking [24] which inadvertently would increase the burden of diabetes care.

The changes in the transition clinic did not significantly improve glycaemic control in this cohort, which is similar to previous follow up studies [26], possibly due to an increase in the number of referrals to the clinic during the second audit and that none of the 
changes in the clinic addressed the mental health aspects of people. However, the transition interventions may have reduced the number of DKA events, as there were non-significantly fewer DKAs in the second audit period. Different models of care have been proposed for improving outcomes of young people with diabetes. Some models involve care delivery by a combination of a transition clinic with a coordinator while others involve either just a clinic or coordinator $[9,15]$. In a meta-analysis, programs that included both a transition coordinator and a dedicated transition clinic were more effective at maintaining glycaemic control and/or preventing its worsening during transition compared to those that involve either component alone, but it was difficult to ascertain which element of the transition programs was most effective at improving diabetes outcomes [15].

\section{Limitations and Strengths}

The study was retrospective with no control group making it difficult to differentiate between the improvements that were related to patient factors from those that were primarily from the intervention. Numbers and period after the change in the clinic were limited. The people were from a single hospital so our results may not apply to other patient groups in regions. The changes were multifaceted, making it difficult to differentiate the effect of any one intervention. We did not enquire about substance use and their effects on DKA and $\mathrm{HbA1c}$, which were shown previously [26] were unaccounted for in our analysis. The retinal screening was performed outside of the hospital and many had not had it performed, which may explain the lack of difference in retinopathy screening. The mental health diagnoses were often not formal due to limited access to mental health services. Routine questionnaire can be administered while the people are waiting. In addition, since this was an audit, we did not provide data on the use of substances such as illicit drugs which was shown to be high in young people with (17.8\%) [26] and without diabetes $(12.7 \%)$ [17] in previous studies but not always documented in clinical data. Despite these limitations, the study has some strengths including the low default rate of people i.e., those that never attended the clinic after the initial referral and the large sample size (largest Australian study to date) compared with previous studies [11].

\section{Conclusions}

The high proportion with a mental health condition and limited access to psychological support were a significant problem strengthening the case for psychologist support into Australian diabetes transition services. Among young people with diabetes, those who smoke, with poor glycaemic control, experience more episodes of DKA and have long-term complications are more likely to have a mental health condition. However, changes to a well-structured multidisciplinary diabetes transition clinic including, an evening clinic and additional staffing did not significantly improve glycaemia with or without a mental health condition. Despite emerging strategies to help young adults with mental health issues, a diagnosis of a chronic disorder is an additional burden. Peer groups for affected individuals to interact with each other improves outcome of people with mental health condition [27]. Furthermore, having an in-house psychologist will initiate early intervention to improve patient satisfaction and optimal diabetes care. Strategies that involve the effective collaboration of primary care providers and mental health specialists/psychologists using principles of measurement-based stepped care and treatment to target the high-risk population identified in this study can substantially improve patients' health and functioning while reducing overall health care costs. 
Author Contributions: Conceptualization, all authors; methodology, U.L.O., A.S., M.R. and D.S.; software, U.L.O., A.S.; validation, all authors; formal analysis, U.L.O., A.S. and D.S.; investigation, all authors; resources, all authors; data curation, A.S., U.L.O. and D.S.; Writing-Original Draft Preparation, U.L.O., M.R., A.S. and D.S.; writing-review and editing, D.S., A.S. and U.L.O.; supervision, D.S. and U.L.O.; project administration, D.S. and U.L.O. All authors have read and agreed to the published version of the manuscript.

Funding: This research received no external funding.

Institutional Review Board Statement: The audit was approved by the South Western Sydney Local Health Research Ethics Committee LNR/16/LPOOL/180.

Informed Consent Statement: Not applicable.

Conflicts of Interest: All authors declared no conflict of interest.

\section{References}

1. Farrell, K.; Griffiths, R.; Fernandez, R. Factors determining diabetes care outcomes in patients with type 1 diabetes after transition from paediatric to adult health care: A systematic review-Protocol. JBI Libr. Syst. Rev. 2009, 7, 1-17.

2. Peters, A.; Laffel, L. Diabetes care for emerging adults: Recommendations for transition from pediatric to adult diabetes care systems: A position statement of the American Diabetes Association, with representation by the American College of Osteopathic Family Physicians, the American Academy of Pediatrics, the American Association of Clinical Endocrinologists, the American Osteopathic Association, the Centers for Disease Control and Prevention, Children with Diabetes, The Endocrine Society, the International Society for Pediatric and Adolescent Diabetes, Juvenile Diabetes Research Foundation International, the National Diabetes Education Program, and the Pediatric Endocrine Society (formerly Lawson Wilkins Pediatric Endocrine Society). Diabetes Care 2011, 34, 2477-2485. [CrossRef]

3. Bernstein, C.M.; Stockwell, M.S.; Gallagher, M.P.; Rosenthal, S.L.; Soren, K. Mental health issues in adolescents and young adults with type 1 diabetes: Prevalence and impact on glycemic control. Clin. Pediatr. 2013, 52, 10-15. [CrossRef] [PubMed]

4. Spaic, T.; Robinson, T.; Goldbloom, E.; Gallego, P.; Hramiak, I.; Lawson, M.; Malcolm, J.; Mahon, J.; Morrison, D.; Parikh, A.; et al. Closing the Gap: Results of the Multicenter Canadian Randomized Controlled Trial of Structured Transition in Young Adults With Type 1 Diabetes. Diabetes Care 2019, 42, 1018-1026. [CrossRef] [PubMed]

5. Bridgett, M.; Abrahamson, G.; Ho, J. Transition, It's More Than Just An Event: Supporting Young People With Type 1 Diabetes. J. Pediatr. Nurs. 2015, 30, e11-e14. [CrossRef]

6. Gupta, A.; Taylor, F.; O'Sullivan, T.; Simmons, D. Characteristics of young adults with multiple episodes of diabetic ketoacidosis. Intern. Med. J. 2019, 49, 911-914. [CrossRef]

7. Nakhla, M.; Daneman, D.; Frank, M.; Guttmann, A. Translating transition: A critical review of the diabetes literature. J. Pediatr. Endocrinol. Metab. 2008, 21, 507-516.

8. Goldenring, J.M.; Rosen, D.S. Getting into adolescent heads: An essential update. Contemp. Pediatr. Montvale 2004, $21,64-92$.

9. Wagner, D.V.; Ulrich, J.; Guttmann-Bauman, I.; Duke, D.C. The process of transition from pediatric to adult diabetes care: Recommendations for US healthcare systems. Diabetes Manag. 2015, 5, 379-391. [CrossRef]

10. Cadario, F.; Prodam, F.; Bellone, S.; Trada, M.; Binotti, M.; Trada, M.; Allochis, G.; Baldelli, R.; Esposito, S.; Bona, G. Transition process of patients with type 1 diabetes (T1DM) from paediatric to the adult health care service: A hospital-based approach. Clin. Endocrinol. 2009, 71, 346-350. [CrossRef]

11. Holmes-Walker, D.; Llewellyn, A.; Farrell, K. A transition care programme which improves diabetes control and reduces hospital admission rates in young adults with Type 1 diabetes aged 15-25 years. Diabet. Med. 2007, 24, 764-769. [CrossRef]

12. Baxter, M.; Hudson, R.; Mahon, J.; Bartlett, C.; Samyshkin, Y.; Alexiou, D.; Hex, N. Estimating the impact of better management of glycaemic control in adults with type 1 and type 2 diabetes on the number of clinical complications and the associated financial benefit. Diabet. Med. 2016, 33, 1575-1581. [CrossRef] [PubMed]

13. National Diabetes Service Scheme (NDSS). Diabetes Map. Available online: https:/ /map.ndss.com.au/\#!/ (accessed on 10 July 2021).

14. Census QuickStats: Sydney—South West. 2016. Available online: https://quickstats.censusdata.abs.gov.au/census_services/ getproduct/census/2016/quickstat/127?opendocument (accessed on 14 July 2020).

15. Schultz, A.T.; Smaldone, A. Components of interventions that improve transitions to adult care for adolescents with type 1 diabetes. J. Adolesc. Health 2017, 60, 133-146. [CrossRef]

16. Yue, D.K.; Colagiuri, S.; McElduff, A.; Silink, M. Diabetes Control and Complications Trial Position statment of the Australian Diabetes Society. Med. J. Aust. 1993, 159, 803-804. [CrossRef] [PubMed]

17. ABS. National survey of mental health and wellbeing: Summary of results. In Statistics on Key Mental Health Issues Including the Prevalence of Mental Disorders, the Associated Disability, and the Use of Services; Australian Bureau of Statistics: Canberra, Australia, 2007.

18. Ducat, L.; Philipson, L.H.; Anderson, B.J. The mental health comorbidities of diabetes. JAMA 2014, 312, 691-692. [CrossRef]

19. Goodwin, J.; Savage, E.; Horgan, A. Adolescents' and young Adults' beliefs about mental health services and care: A systematic review. Arch. Psychiatr. Nurs. 2016, 30, 636-644. [CrossRef] 
20. Penninx, B.W.J.H.; Lange, S.M.M. Metabolic syndrome in psychiatric patients: Overview, mechanisms, and implications. Dialogues Clin. Neurosci. 2018, 20, 63-73. [CrossRef] [PubMed]

21. Mendelsohn, C.P.; Kirby, D.P.; Castle, D.J. Smoking and mental illness. An update for psychiatrists. Australas. Psychiatry 2015, $23,37-43$. [CrossRef] [PubMed]

22. Cooper, J.; Mancuso, S.G.; Borland, R.; Slade, T.; Galletly, C.; Castle, D. Tobacco smoking among people living with a psychotic illness: The second Australian Survey of Psychosis. Aust. N. Z. J. Psychiatry 2012, 46, 851-863. [CrossRef]

23. Williams, J.M.; Steinberg, M.L.; Griffiths, K.G.; Cooperman, N. Smokers with behavioral health comorbidity should be designated a tobacco use disparity group. Am. J. Public Health 2013, 103, 1549-1555. [CrossRef]

24. Greenhalgh, E.; Stillman, S.; Ford, C. 7.12 Smoking and Mental Health; Cancer Council Victoria: Melbourne, Australia, 2018.

25. Forman-Hoffman, V.L.; Hedden, S.L.; Glasheen, C.; Davies, C.; Colpe, L.J. The role of mental illness on cigarette dependence and successful quitting in a nationally representative, household-based sample of US adults. Ann. Epidemiol. 2016, 26, 447-454. [CrossRef] [PubMed]

26. Shah, V.N.; Taylor, D.D.; Foster, N.C.; Beck, R.O.Y.; Akturk, H.K.; Kinney, G.L. 836-P: Cannabis Use in Adults with Type 1 Diabetes (T1D) Is Associated with Poor Glycemic Control and Increased Risk for Diabetic Ketoacidosis (DKA). Diabetes 2019, 68. [CrossRef]

27. Ali, K.; Farrer, L.; Gulliver, A.; Griffiths, K.M. Online peer-to-peer support for young people with mental health problems: A systematic review. JMIR Ment. Health 2015, 2, e4418. [CrossRef] [PubMed] 